NASA Technical Memorandum 85744

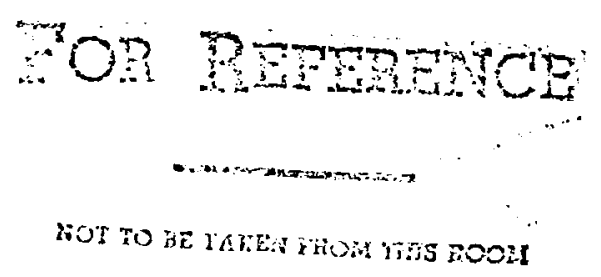

\title{
AIRCRAFT AND BACKGROUND NOISE ANNOYANCE EFFECTS
}

KELLI F. WILLSHIRE

JANUARY 1984
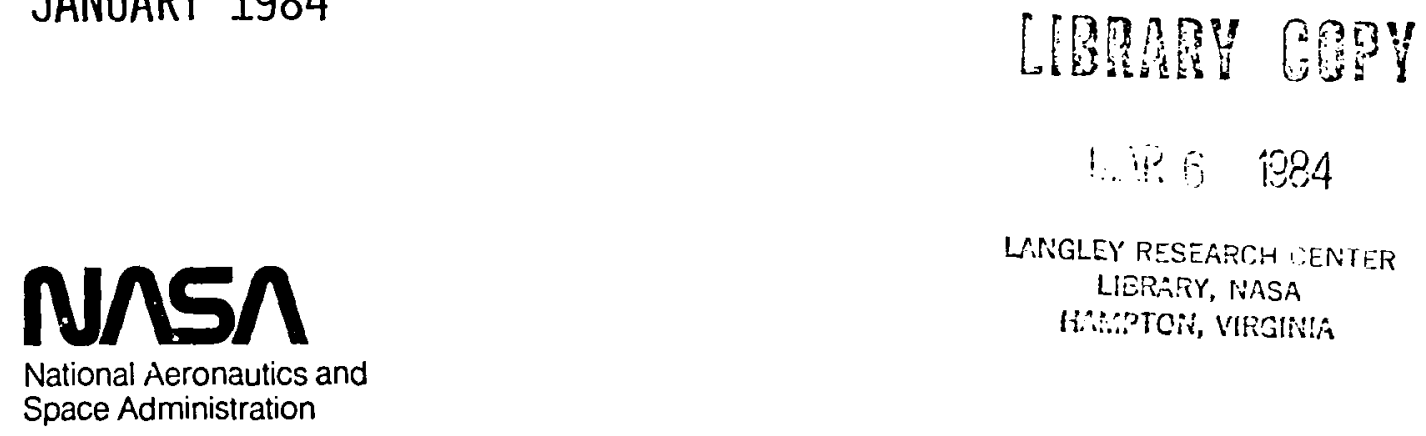

LARGLEY RESEARCH :SENTER

LIERARY, NASA

Hi.:.:?TCir, VIRGINIA

Space Administration

Langley Research Center

Hampton, Virginia 23665 



\section{SUMMARY}

Traditionally, community aircraft flyover annoyance has been studied in the absence of other noises. However, the importance of considering the flyovers along with other community noise sources, which is more representative of the real world, is gaining awareness. This paper presents the results from two experiments directed toward understanding annoyance response to combined sources. As a first step in understanding annoyance response to combined sources, baseline annoyance responses to the individual sources are necessary. The purpose of the first experiment was to establish the relationships between annoyance and noise level for three community noise sources presented individually. These noise sources were jet aircraft flyovers, air conditioner, and traffic. The second experiment investigated the effects of combined sources on annoyance. Specifically, the effects of aircraft to background noise level difference (signal-to-noise ratio), type of background noise source (spectrum), and total noise level on rated annoyance were determined.

Results indicated that the slope of the linear relationship between annoyance and noise level for traffic noise was significantly different from that of flyover and air conditioner noise. This indicated that further research was justified to determine the influence of the two background noises on overall, aircraft, and background noise annoyance (e.g., experiment two). In experiment two, total noise exposure, signal-to-noise ratio, and background source type were found to have effects on total as well as source specific annoyance responses. Thus, both signal-to-noise ratio, and the background source must be considered when trying to determine community response to combined noise sources.

\section{INTRODUCTION}

Historically, most research on human response to community noise has focused on the effect of a particular noise source, especially aircraft noise, upon annoyance. However, there is increased awareness of the importance of considering multiple noise sources in the community, because this is more representative of the real world. Despite the more recent investigations of annoyance to combined noise sources (refs. 1, 2, and 3), the relative contributions of various major noise sources to annoyance have not been clearly established. In particular, the effects of background or ambient noise have not been well defined. Background noise is the noise or noises present other than the major noise of interest, such as aircraft flyover noise.

The most common noise sources investigated in the laboratory are traffic, aircraft, and train, which produce similar slopes when annoyance rating scores are plotted against noise level. Even though these noises have different temporal characteristics, the rate of increase in annoyance with noise level is about the same for all of them (refs. 1 and 2). Consequently, most community noise response models assume equal slopes (but not necessarily equal intercepts). This paper describes two experiments conducted to obtain additional data for understanding and assessing human annoyance response to aircraft and background noise, both individually and in combination. 
Results of these experiments will provide data for use in the ultimate development of a model of community noise response that would account for background noise effects. To increase the generality of such a model, the annoyance response to an additional community noise source, which has different characteristics from the more commonly studied aircraft and traffic noise should be considered. Thus, the purpose of the first experiment was to determine the relationships between annoyance responses and noise level for the individual sources. A particular objective was to determine if the relationships had equal slopes. The sources considered were jet aircraft flyover noise, traffic noise, and air conditioner noise. Results of this experiment would provide baseline data for comparison of the sources when presented in combination. The purpose of the second experiment was to determine annoyance responses to combined sources.

\section{EXPERIMENTAL METHOD}

Experiment 1

Subjects

Forty-eight subjects were selected from a contractual pool of local community residents and were paid for their participation. There were 6 males and 42 females whose combined average age was 40.5 years. All subjects were given audiograms to ensure normal hearing ability.

\section{Test Facility}

The interior effects room (IER) in the NASA Langley Aircraft Noise Reduction Laboratory was used for the research. (See figure 1). This room is designed to resemble a typical living room and to allow controlled acoustical environments to be presented to subjects. The IER is suspended with steel rods within a reinforced concrete outer room $(3.7 \mathrm{~m} \times 7.1 \mathrm{~m} \times 8.3 \mathrm{~m})$ over an open basement. This arrangement provides vibration and acoustic isolation of the test area. Loudspeakers used to produce the noise stimuli are located outside the test room above the ceiling and beside the walls to provide a realistic simulation of residential outdoor noise.

\section{Apparatus}

Stimuli presentation system.- A computer controlled tape recorder system was used to play back recorded flyover noise stimuli at the appropriate level and number of times during each session. The traffic and air conditioner noise stimuli were reproduced on a separate tape recorder, and the levels were controlled manually with attenuators.

Questionnaire.- Annoyance is the primary dependent variable of interest, because this response to community noise is the one with which most people are 
concerned. Annoyance is defined as the unwantedness of the sound. Subjects rated annoyance on an eleven point, unipolar category rating scale with anchor lables. That is, the scale ranges from 0 to 10 with the words "not annoying at all" and "extremely annoying" at the respective endpoints. Subjects were asked to rate the degree of annoyance for the noise in each session.

In addition, after the last session for every subject group, each subject was asked to complete another questionnaire. The purpose of this questionnaire was to obtain a reference point on the annoyance scale and also to allow comparisons with previous studies. The question asks the subject to indicate at what point on the $0-10$ scale the subject would start to become highly annoyed. Subject instructions and questionnaires are given in Appendix 1.

\section{Noise Stimuli}

Three types of noise stimuli, reproduced at various levels, were used: jet aircraft flyover, air conditioner, and traffic. For the aircraft flyover stimuli, a tape recording made approximately $4.8 \mathrm{~km}$ from touchdown of a Boeing 727 landing was used. Each flyover had a total duration of approximately 20 sec. The duration at $10 \mathrm{~dB}$ down from the peak was approximately $14 \mathrm{sec}$. An average one-third octave band spectrum as measured in the center of the test room is reproduced in figure $2(a)$. The spectrum is the energy-averaged sound pressure level in A-weighted sound level $\left(L_{A}\right)$ over all .5 sec. intervals of the flyover for each one-third octave band. The time history of one flyover within a 3 min. sample is shown in figure $3(a)$.

The traffic noise stimuli was a recording made approximately $100 \mathrm{~m}$ from the near lane of a limited access four-lane divided highway during a period of moderate traffic flow. The noise is representative of freely flowing high speed road traffic. In this recording, truck traffic events and most automobile events are usually distinguishable. The energy-averaged spectrum in $L_{A}$ over a 3 min. sample is shown in figure $2(b)$, and the time history is shown in figure $3(b)$.

The air conditioner noise stimuli was recorded from a typical home central air conditioning unit located outdoors. The recording was made at a distance of $1 \mathrm{~m}$. The noise was filtered at $800 \mathrm{~Hz}$ and above to eliminate a high frequency background hiss. The spectrum as measured from the center of the test room is illustrated in figure $2(c)$, and the time history is given in figure $3(c)$.

The three types of noise stimuli have been compared for spectral characteristics. Generally, the air conditioner noise energy is concentrated in the lower frequencies $(63-900 \mathrm{~Hz})$. The traffic noise is more broadband and contains more energy in the moderate frequencies (63-4000 Hz) when averaged over a period of time. Individual traffic noise spectra may differ widely in content. The flyover noise contains more energy in the high frequencies than either of the two background noises. Temporally, both the traffic and air conditioner noise are continuous whereas, the flyover noise is intermittent in that it only occurs for short durations. 
Design

The experimental design of Experiment 1 was a $3 \times 4$ complete factorial repeated measures design in which every subject received all twelve treatment combinations. (See Table I). The two variables were noise source (aircraft flyover, air conditioner, and traffic) and noise level $(40,48,56,65$ indoor Leq). (Leq is the energy averaged noise level integrated over a specified period of time. In this experiment, the time was $10 \mathrm{~min}$., and the Leq was A-weighted). Each treatment condition was presented over one $10 \mathrm{~min}$. session. Three flyovers were presented during each aircraft flyover session. In addition, the first condition presented to each subject was repeated. A balanced presentation scheme was used, and each group of 12 subjects received a different presentation order.

\section{Procedure}

Upon arrival at the laboratory, the subjects were seated in the four chairs of the IER. The test conductor reviewed the instructions and questionnaires and answered any questions that the subjects had. The subjects were instructed to sit during all sessions and were asked not to talk. For all sessions, subjects were instructed to respond to the questionnaire after the end of each session. The intersession interval was approximately $1 \mathrm{~min}$. , and a $15 \mathrm{~min}$. break was provided after the seventh session.

Experiment 2

Subjects

This experiment used 216 subjects selected from the same local subject pool. These subjects did not participate in the first experiment. The mean age of the subjects was 35.9 years. They were paid and were given audiograms as was done in Experiment 1.

Test Facility

The same test facility (the interior effects room) used in Experiment 1 was used for this experiment.

\section{Apparatus}

Stimuli presentation system.- The same systems for stimuli presentation used in the first experiment was used in this experiment.

Questionnaires.- Three different annoyance questions were asked. One question asked the subjects to rate the degree of annoyance for the noise in the session, total annoyance, as was done in the first experiment. However in this 
experiment, total annoyance resulted from both the background and flyover noise. Two other questions measured source specific annoyance of the background and of the flyovers. That is, one question asked "How annoying was the aircraft noise?", and the other question asked "How annoying was the background noise?". At the end of the experiment, each subject was asked to indicate the point at which they became highly annoyed, as in Experiment 1. The questionnaire for Experiment 2 is in Appendix 2.

\section{Noise Stimuli}

The same stimuli used in the first experiment were used in this experiment. However, rather than presented separately, the stimuli were presented in combination as described in the design section below. Examples of the time histories from the combined sources are shown in figure 4.

\section{Design}

This experiment used a $3 \times 2 \times 6$ split-plot repeated measures design, shown in Table II. The subjects were blocked by total noise exposure $(45,55,65$ indoor Leq) with 72 subjects in each block. Total Leq is the combined Leq of the three flyovers and the continuous background noise. The two within subject variables were two background noise sources, air conditioner and traffic, and six signal-to-noise ratios $(S / N)$ (plus and minus 3, 9, and $15 \mathrm{~dB}$ ). Signal-tonoise ratio is defined as the difference (in $\mathrm{dB}$ ) between the Leq of three aircraft flyovers and the background noise Leq. The background noise sources are distinguishable by their spectral content and temporal characteristics as shown earlier in figures 2 and 3.

Each subject, in groups of four, received all combinations of background type and S/N, for a given total Leq. Each combination was presented over one 10 minute session. The flyover and background level used to achieve the desired overall levels and S/N'S are given in Table III. In addition to the twelve conditions, two anchor conditions were presented to allow comparison of the flyovers as an individual noise source across both experiments. Each anchor condition was one 10 minute session of either three highest level or lowest level flyovers used in Experiment 1, e.g., 40 or 65 Leq.

One-half of the subjects received all the air conditioner sessions first and the other half received the traffic conditions first. These were split evenly anong the three overall Leq level blocks. In addition, presentation order within each of the blocks was counterbalanced. The actual presentation orders are listed in Table IV. In total, each group of subjects received 14 different 10 minute sessions. 
Procedure

The procedure for this experiment is the same as that used in Experiment 1.

\section{RESULTS}

\section{Experiment 1}

The order of presentation was not significant. Accordingly, data pooled across presentation order were used in the analysis. Furthermore, only data from twelve of the thirteen sessions were used for each subject. The first session was treated as a practice session. From a multivariate analysis of variance for repeated measures the main effects of noise source and noise level were both significant, as shown in Table $V$. The mean annoyance response for each noise source as a function of noise level is plotted on figure 5 . These data indicate a noise source by noise level interaction, which was verified by the multivariate analysis of variance. Traffic noise was the most annoying and became increasingly so as noise level increased.

The annoyance responses were corrected according to each subject's rating for the point at which the subject is highly annoyed. If the subject's annoyance response for a session was greater than or equal to the subject's rating for highly annoyed, the session response was scored as a 1. 0therwise it was scored as a 0 . Analysis of these dichotomous data pooled across groups also indicated a significant source by level interaction, $F(6,282)=2.26, \underline{p}<.05$. (Presentation order was not significant). In addition, both main effects of noise source and noise level was significant, $F(2,94)=8.47 p<.01$ and $F(3,141)=49.23, p<.01$, respectively. The rating of 7.2 was the mean rating score of the point of being highly annoyed. Stimuli were rated as being highly annoying $28 \%$ of the time.

A first order multiple regression with interaction terms was performed over all the data (excluding session one). The following model was tested:

$$
Y=B_{0}+B_{1} L+B_{2} D_{2}+B_{3} D_{3}+B_{4} L D_{2}+B_{5} L D_{3}
$$

Where $Y=$ annoyance, $B=$ regression coefficient for each term, $L=$ noise level, $D_{2}=$ dummy variable for air conditioner, $D_{3}=$ dummy variable for traffic. An explanation for the use of dummy variables in regression analysis can be found in Reference 4.

As shown in Table VI, this model resulted in a significant multiple regression (stepwise) correlation coefficient, $R=.62136$. The percent of variance $\left(R^{2}\right)$ accounted for by all of the terms was $38.61 \%$. However, noise level itself accounted for $85 \%$ of the total explained variance.

Further regression analyses were performed to test the difference between regression slopes of the annoyance response functions for each source. Indivi- 
dual regression analyses were run for each source for each subject using the full model described earlier. Because dummy variable coding was used, the resulting regression coefficients represented the difference in slope between the two sources tested (included in the model) and the reference slope (the source omitted from the model). Thus two regressions were run for each subject. One model included traffic and air conditioner terms relative to flyover, and the other model included traffic and flyover terms relative to air conditioner. These two analyses provided comparisons of the three sources' slopes (regression coefficients). From the individual regression coefficients for each source, a mean regression coefficient and standard error of the mean were calculated. This mean was tested against the hypothesis that all slopes (regression coefficients) were equal, $H=0$, using a $z$-score transformation. (A $z$-score is a standard normal score of the means as described in Reference 5).

The results indicated that the slope associated with traffic noise was significantly different from that of air conditioner, $z(\underline{\alpha}=.05)=4.64$, and also significantly different from the flyover, $\underline{z}(\underline{\alpha}=.05) \equiv 2.58$. However, the slopes of air conditioner and flyover were not significantly different, $\underline{z}(\underline{\alpha}=$ $.05)=1.13$.

\section{Experiment 2}

This section presents preliminary results from the second experiment. Consequently, discussion is limited to the major findings obtained to date. The primary objective of Experiment 2 was to determine whether the type of background noise differentially affected annoyance. Of additional interest was the determination of the effect of total Leq and $S / N$ on annoyance.

From an analysis of variance for repeated measures (not shown), the main effects of total Leq, background source, and $S / N$ were significant for all three types of rated annoyance: total, aircraft, and background.

When subjects were asked to rate aircraft annoyance, the interaction of background source with $S / N$ was significant, which is illustrated in figure 6 . This figure shows that aircraft annoyance was high, but relatively constant, across $S / N$ for traffic background noise, and increased with $S / N$ for air conditioner background noise. A similar, but not as strong, interaction was found for total annoyance. (See figure 7). In this case, the annoyance during air conditioner background was relatively constant, while that for traffic background decreased slightly with increasing $S / N$.

Comparisons of the three types of rated annoyances, averaged over background source type, revealed significant differences across $S / N$, as shown in figure 8. Aircraft noise annoyance increased slightly with $S / N$, while background and total noise annoyance decreased.

Note that aircraft noise annoyance was highest, followed by total noise annoyance (which included ratings of both the aircraft and the background), and then background annoyance. 


\section{DISCUSSION AND CONCLUDING REMARKS}

The first experiment established annoyance-noise level functions for each individual noise source. Furthermore, these sources were found to interact across noise level. Annoyance to traffic noise had a greater slope over noise level than did annoyance to air conditioner noise or to flyover noise. There was no difference between the latter two noise sources.

Different spectra for air conditioner and traffic may explain part of the difference in slope for these sources. However, this does not explain the finding of no difference in slope between the air conditioner and flyover noises. The flyover noise occurred for shorter periods of time compared to the continuous air conditioner noise. Thus, duration may have been a factor in negating any differences due to spectra. While the slopes were found to be equal for these two sources, a difference between them was not hypothesized. Only a difference between air conditioner and traffic was hypothesized, which was supported. Also, only linear regression slopes were considered. Examination of the data indicates that a quadratic factor may be present in the flyover noise annoyance function. This will be considered in future analyses of the data.

Given the results of differences between the slopes of the noises, further investigation of the effects of combined noise sources was warranted. This is because a difference between the function slopes of two background sources may differentially affect annoyance when each source is combined with flyover noise.

The second experiment investigated the effects of the combined noise sources on annoyance. The effects of signal to noise ratio and total Leq on both overall annoyance and source specific annoyance, e.g., aircraft and background noise annoyance, were determined.

The effect of $S / N$ for each background source on aircraft and total annoyance (figs. 6 and 7 ) can probably be explained by the temporal characteristics of the cornbined sources. The greater intermittency of the flyovers as compared to the steady air conditioner background may make the flyover noise more noticeable as $S / N$ increases, and thus elicit higher annoyance responses. But because there was less difference in intermittency between the traffic noise and flyovers, the flyovers may not have been as noticable resulting in little change in annoyance responses. Also the spectral differences between the lower frequency air conditioner noise and higher frequency flyover noise make them more disparate. Further, the broadband traffic noise could mask more of the flyover noise, due to closer contiguous masking bands, than could the air conditioner noise. This would also tend to make the flyover noise less distinguishable against the traffic noise. However, masking may not be the only process responsible for this result. Further analysis is necessary to resolve the importance of background noise source and $S / N$ in the determination of subjective annoyance judgements.

The differences observed across $S / N$ for the three types of annoyance response (fig. 8 ), may be attributable to two phenomena. Recall that aircraft annoyance was greater than total annoyance which was greater than background annoyance. Intuitively, it would seem that total annoyance would be greatest 8 
because it represents annoyance due to the combined effects of the aircraft and background noises. However, the results of this experiment (and others) did not support simple annoyance summation. Two explanations offered for these results are inhibition and expectation. Inhibition would imply that total annoyance was modified or inhibited perceptually by the presence of one of the sources, most likely the background source. Expectation theory would imply that people expect aircraft to be highly annoying and thus rate it in that manner. Background noise is not expected to be as annoying and thus is rated lower. Consequently, when asked to rate both noises in combination, a cognitive subtractive process occurs. Exactly how these phenomena operate or which is correct has been debated by various investigators and will not be reviewed here. The explanation of these preliminary results will be the object of further investigation.

In summary, the results of these experiments indicate that the type of background noise source must be considered for annoyance of combined sources, and that $S / N$ is very important. Ultimately, these data will provide a basis for the development of a community noise response model that accounts for both the effects of background noise and $S / N$.

\section{REFERENCES}

1. Flindell, I. H.: Community Response to Multiple Noise Sources. Ph.D. Dissertation, University of Southampton, England, 1982.

2. Powe11, C. A.: Annoyance Due to the Interaction of Community Noise Sources. Ph.D. Dissertation, George Washington University, 1978.

3. Taylor, S. M.; Hall, F. L.; and Birnie, S. E.: Effect of Background Levels on Community Responses to Aircraft Noise. Journal of Sound and Vibration, $1980,71(2), 261-270$.

4. Kerlinger, F. N.; and Pedhazur, E. J.: Multiple Regression in Behavioral Research. New York: Holt, Rinehart, and Winston, 1973.

5. Hughes, A.; and Grawoig, D.: Statistics: A foundation for Analysis. MA: Add ison-Wesley, 1971. 
APPENDIX 1

Instructions and Questionnaires for Experiment 1

\section{Instructions}

The experiment in which you are participating today is to help us understand the reactions of people to various aircraft noise environments. There will be several sessions of noises during which you may hear traffic, air conditioner, or aircraft flyover noise. Each session will last about 10 minutes. There will be a break after half of the sessions.

During all of the sessions, we request that you stay seated, but feel free to read. We ask that you talk as little as possible and do not do any handwork (e.g., knitting). There will be a short beep at the end of every session. At that time we would like you to make a judgment about the noises you just heard.

A set of response sheets, one for each session, will be given to you at the start of the test. Please be sure that you record your judgments on the appropriate sheet for the session concerned. The session number will be written on each response sheet. The response sheet will have one scale numbered horizontally "0 to 10" for each session. The end points are labeled "NOT ANNOYING AT ALL" and "EXTREMELY ANNOYING." Your judgment in all cases should be indicated by circling one of the numbers on the scale with the pencil provided. For example, if you judge the noise to be very annoying, then you should circle a number closer to the "EXTREMELY ANNOYING" end of the scale. Similarly, if you judge the noise to be only slightly annoying, you should circle a number closer to the "NOT ANNOYING AT ALL" end of the scale. The first response sheet will serve as an example. Remember to make a judgment at the end of each session when you hear a single beep. The beginning of the next session will be signaled by two short beeps.

There are no correct answers; we just want a measure of your own personal reaction to the noises in each session. For this reason, we request that you do not talk about the noise, especially while responding to questions on the response sheets and do not attempt to compare judgments.

Thank you for participating in this investigation. 
Session Questionnaire for Experiment 1

$$
\text { Session Questionnaire }
$$

$\begin{array}{lll}\text { Group } & \text { Test } & \text { Session } \\ \text { Subject No. } & \text { Date }\end{array}$

How annoying was the noise in the session?

$\begin{array}{llllllllllllll}\text { Not Annoying At All } & 0 & 1 & 2 & 3 & 4 & 5 & 6 & 7 & 8 & 9 & 10 & \text { Extremely Annoying }\end{array}$ 
Questionnaire

$\begin{array}{lll}\text { Group } & \text { Test } & \text { Session } \\ \text { Subject No. } & \text { Date }\end{array}$

At what point on your scale would you start to become highly annoyed? In other words, at what point on the scale would you consider doing something about the noise, such as moving or complaining to authorities?

Not Annoying At All $\begin{array}{lllllllllllll}0 & 1 & 2 & 3 & 4 & 5 & 6 & 7 & 8 & 9 & 10 & \text { Extremely Annoying }\end{array}$ 


\section{APPENDIX 2}

Instructions and Questionnaires for Experiment 2

\section{Instructions}

The experiment in which you are participating today is to help us understand the reactions of people to various aircraft noise environments. There will be several sessions of noises during which you may hear traffic, air conditioner and/or aircraft flyover noise. Each session will last about 10 minutes. There will be a break after half of the sessions.

During all of the sessions, we request that you stay seated, but feel free to read. We ask that you talk as little as possible and do not do any handwork (e.g.. knitting). There will be a short beep at the end of every session. At that time we would like you to make a judgment about the noises you just heard.

A set of response sheets, one for each session, will be given to you at the start of the test. Please be sure that you record your judgments on the appropriate sheet for the session concerned. The session number will be written on each response sheet. The response sheet will have one scale numbered horizontally "O to 10" for each session. The end points are labeled "NOT ANNOYING AT ALL" and "EXTREMELY ANNOYING." Your judgment in all cases should be indicated by circling one of the numbers on the scale with the pencil provided. For example, if you judge the noise to be very annoying, then you should circle a number closer to the "EXTREMELY ANNOYING" end of the scale. Similarly, if you judge the noise to be only slightly annoying, you should circle a number closer to the "NOT ANNOYING AT. ALL" end of the scale. The first response sheet will serve as an example. Remember to make a judgment at the end of each session when you hear a single beep. The beginning of the next session will be signaled by two short beeps.

There are no correct answers; we just want a measure of your own personal reaction to the noises in each session. For this reason, we request that you do not talk about the noise, especially while responding to questions on the response sheets and do not attempt to compare judgments.

Thank you for participating in this investigation. ; w 
Session Questionnaire for Experiment 2

$$
\text { Session Questionnaire }
$$

$\begin{array}{lll}\text { Group } & \text { Test } & \text { Session } \\ \text { Subject No. } & \text { Date }\end{array}$

1. How annoying was the noise in the session?

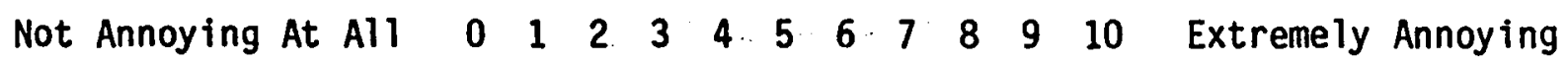

2. Specifically, how annoying was the aircraft noise?

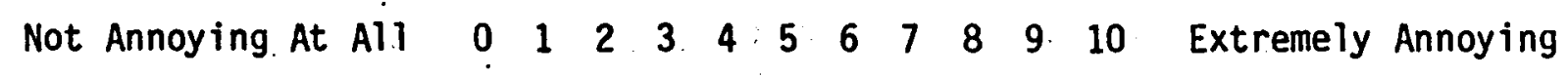

3. Specifically, how annoying was the background noise?

Not Annoying At All $\quad 0 \begin{array}{llllllllllll}0 & 2 & 3 & 4 & 5 & 6 & 7 & 8 & 9 & 10 & \text { Extremely Annoying }\end{array}$ 


\section{Questionnaire}

$\begin{array}{lll}\text { Group } & \text { Test } & \text { Session } \\ \text { Subject No. } & \text { Date }\end{array}$

At what point on your scale would you start to become highly annoyed? In other words, at what point on the scale would you consider doing something about the noise, such as moving or complaining to authorities?

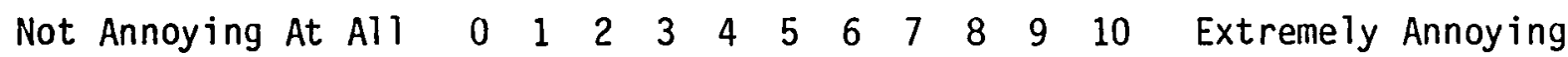


Table 1.- Experimental Design: Experiment $1^{\mathrm{a}}$

\begin{tabular}{|l|c|c|c|c|}
\hline \multirow{2}{*}{$\begin{array}{l}\text { Soise } \\
\text { Stimulus }\end{array}$} & \multicolumn{3}{|c|}{ Indoor Sound Level, Leq (dBA) } \\
\cline { 2 - 5 } Aircraft & 40 & 48 & 56 & 65 \\
\hline Flyover & & & & \\
Traffic & & & & \\
\hline Air \\
Conditioner
\end{tabular}

a Every subject received every treatment combination. 
Table II.- Experimental Design: Experiment 2

\begin{tabular}{|c|c|c|c|c|c|c|c|c|c|c|c|c|c|c|}
\hline \multirow{4}{*}{$\begin{array}{l}\text { Total } \\
\text { Noise } \\
\text { Exposure } \\
\text { Leq, dBA }\end{array}$} & \multirow{4}{*}{$\begin{array}{l}G \\
R \\
0 \\
U \\
P\end{array}$} & \multirow{4}{*}{$\begin{array}{l}S \\
U \\
B \\
J \\
E \\
C \\
T \\
\\
N \\
0 .\end{array}$} & \multicolumn{12}{|c|}{ BACKGROUND NOISE SOURCE } \\
\hline & & & \multicolumn{6}{|c|}{ Air Conditioner } & \multicolumn{6}{|c|}{ Traffic } \\
\hline & & & \multicolumn{6}{|c|}{ Signal-to-Noise Ration, $d B$} & \multicolumn{6}{|c|}{ Signal-to-Noise Ratio, dB } \\
\hline & & & -15 & -9 & -3 & 3 & 9 & 15 & -15 & -9 & -3 & 3 & 9 & 15 \\
\hline 45 & $\begin{array}{l}1 \\
\dot{\bullet} \\
\dot{6}\end{array}$ & $\begin{array}{c}1-4 \\
\dot{-} \\
69-72\end{array}$ & & & & & & & & & & & & \\
\hline 55 & $\begin{array}{r}7 \\
\bullet \\
12\end{array}$ & $\begin{array}{c}73-76 \\
\dot{\bullet} \\
141-144\end{array}$ & & & & & & & & & & & & \\
\hline 65 & $\mid \begin{array}{r}13 \\
\dot{.} \\
18\end{array}$ & $\begin{array}{c}145-148 \\
\dot{\bullet} \\
213-216\end{array}$ & & & & & & & & & & & & \\
\hline
\end{tabular}


Table III.- Noise Level Combinations: Experiment $2^{a}$

\begin{tabular}{|c|c|c|c|}
\hline $\begin{array}{c}\text { Total } \\
\text { Noise } \\
\begin{array}{c}\text { Exposure } \\
\text { Leq, dBA }\end{array}\end{array}$ & $\begin{array}{c}\text { Signal } \\
\text { to } \\
\text { Noise } \\
\text { Ratio, dB }\end{array}$ & $\begin{array}{c}\text { Background } \\
\text { Leve1 } \\
\text { Leq, dBA }\end{array}$ & $\begin{array}{c}\text { Aircraft } \\
\text { Flyover } \\
\text { Level } \\
\text { Leq, dBA }\end{array}$ \\
\hline & -15 & 45 & 30 \\
45 & -9 & 45 & 36 \\
& -3 & 43 & 40 \\
& +3 & 40 & 43 \\
& +9 & 36 & 45 \\
& +15 & 30 & 45 \\
\hline 55 & -15 & 55 & 40 \\
& -9 & 55 & 46 \\
& -3 & 53 & 50 \\
& +3 & 50 & 53 \\
& +9 & 46 & 55 \\
& +15 & 40 & 55 \\
\hline 65 & -15 & 65 & 50 \\
& -9 & 65 & 56 \\
& -3 & 63 & 60 \\
& +3 & 60 & 63 \\
& +9 & 56 & 65 \\
& +15 & 50 & 65 \\
\hline & & &
\end{tabular}

a All levels given as measured in center of test room. 
Table IV.- Presentation Orders for Experiment 2

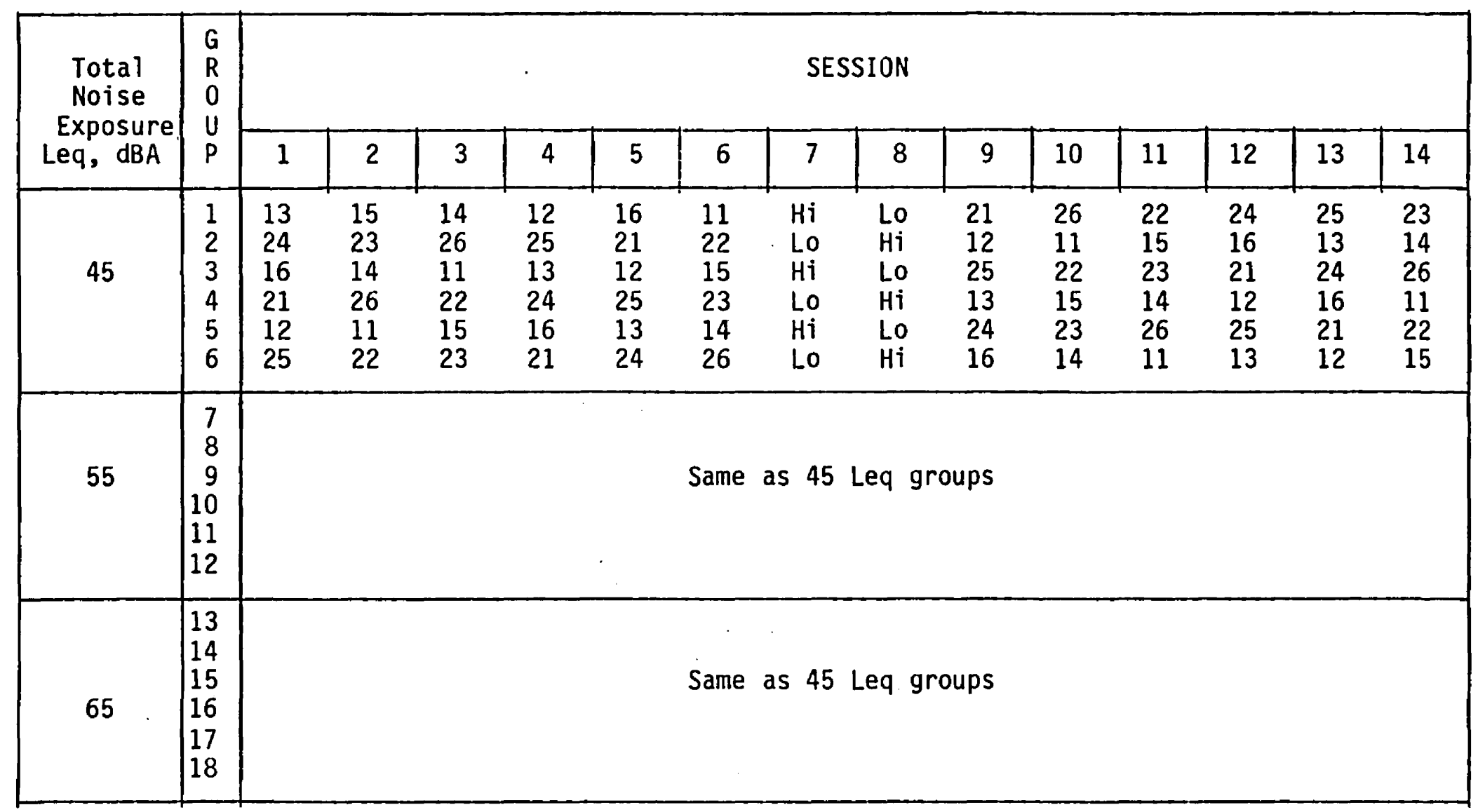

\begin{tabular}{|c|cc|}
\hline Stimuli Key & \\
\hline First digit: $1=$ Air Conditioner & Second digit: & $1=-15 \mathrm{~dB}$ \\
$2=$ Traffic & (Signal-to- & $2=-9 \mathrm{~dB}$ \\
Noise Ratio) & $3=-3 \mathrm{~dB}$ \\
& & $4=+3 \mathrm{~dB}$ \\
Hi $=$ Flyover only, 65 Leq & $5=+9 \mathrm{~dB}$ \\
Lo = Flyover only, 40 Leq & & $6=+15 \mathrm{~dB}$ \\
& & \\
\hline
\end{tabular}


Table V.- Summary of Analysis of Variance: Experiment 1 (Across Groups)

\begin{tabular}{|c|c|c|c|}
\hline Source & $\begin{array}{c}\text { Degrees of } \\
\text { Freedom }\end{array}$ & $\begin{array}{l}\text { Mean } \\
\text { Square }\end{array}$ & $\begin{array}{c}\text { F-ratio } \\
\text { (a) }\end{array}$ \\
\hline Between subjects $\ldots \ldots \ldots \ldots \ldots \ldots \ldots$ & 47 & 29.16 & \\
\hline Within subjects & 528 & & \\
\hline Noise source $\ldots \ldots \ldots \ldots \ldots \ldots \ldots \ldots$ & 2 & 123.59 & $19.41 *$ \\
\hline Source $\times$ subj. within groups ....... & 94 & 6.37 & \\
\hline 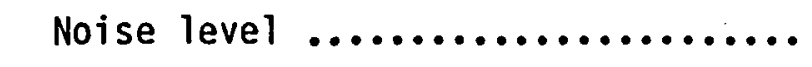 & 3 & 552.24 & $197.98 *$ \\
\hline Level $\times$ subj. within groups ........ & 141 & 2.79 & \\
\hline Source $\times$ level $\ldots \ldots \ldots \ldots \ldots \ldots \ldots \ldots$ & 6 & 9.51 & $4.50 *$ \\
\hline Source $\times$ level $\times$ subj. within groups & 282 & 2.11 & \\
\hline Total & 575 & & \\
\hline
\end{tabular}

asuperscript * indicates significant at 0.01 level. 
Table VI.- Stepwise Multiple Regression of Annoyance: Experiment 1

\begin{tabular}{|c|c|c|c|c|}
\hline Variable & Coefficient & F to Enter Equation & $R$ & Change in $R^{2}$ \\
\hline $\mathrm{L}$ & .17383 & 281.76365 & .57381 & .32925 \\
$\mathrm{LD}_{3}$ & .04094 & 50.67435 & .61948 & .05450 \\
$\mathrm{D}_{3}$ & -.69128 & 1.23371 & .62055 & .00133 \\
$\mathrm{D}_{2}$ & 1.19854 & .28329 & .62079 & .00030 \\
$\mathrm{LD}_{2}$ & -.02055 & .65926 & .62136 & .00071 \\
Constant & -5.92624 & & & \\
\hline
\end{tabular}




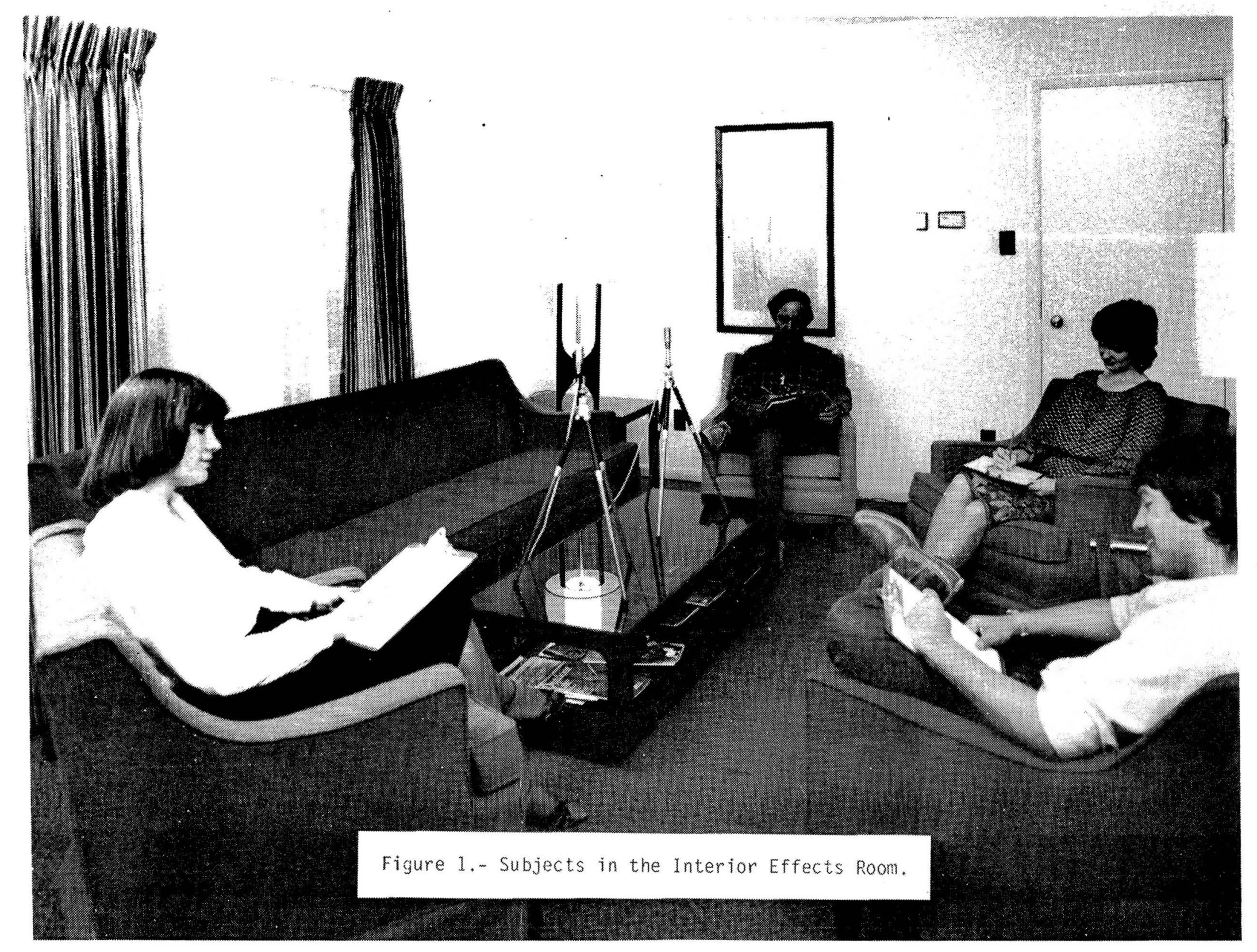




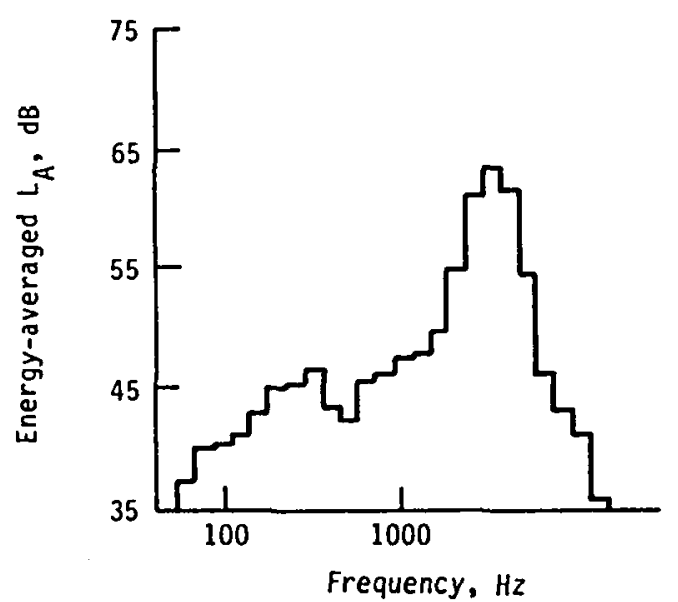

(a) Aircraft flyover noise spectra.

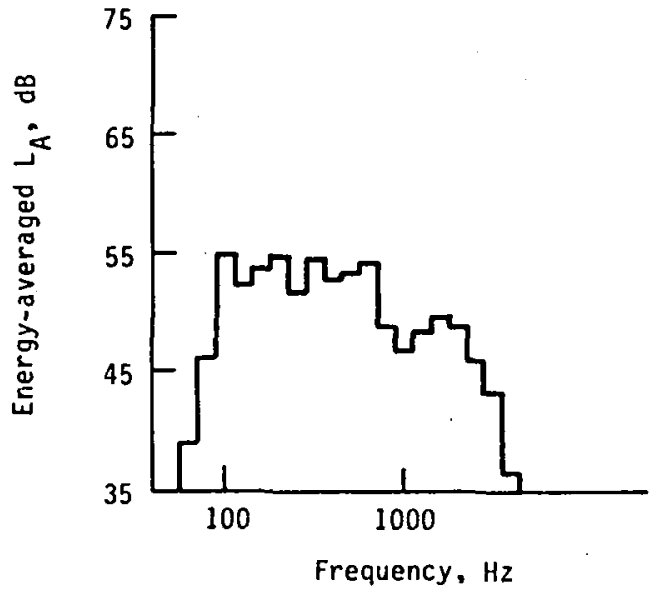

(b) Traffic noise spectra.

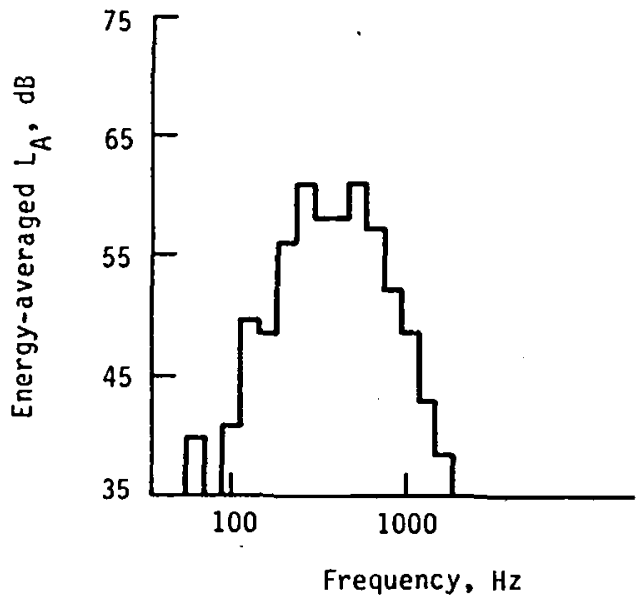

(c) Air conditioner noise spectra.

Figure 2.- One-third octave band spectra of stimuli. 


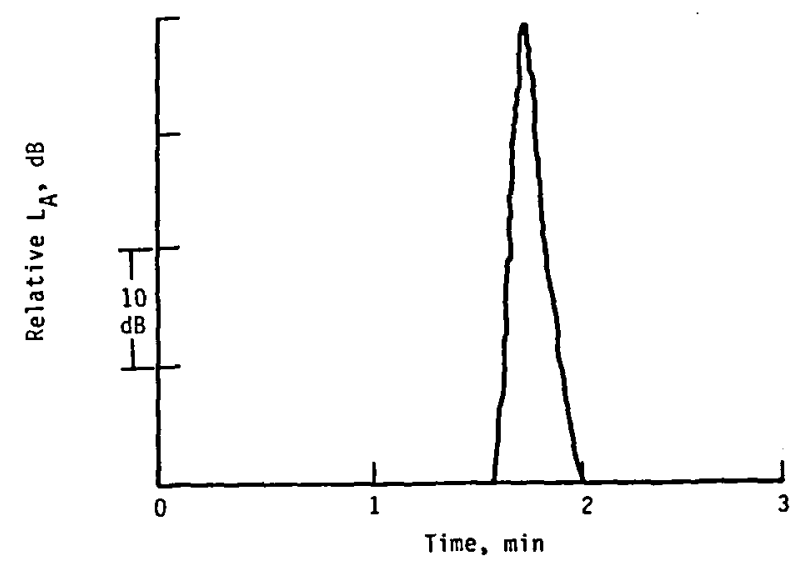

(a) Aircraft flyover.

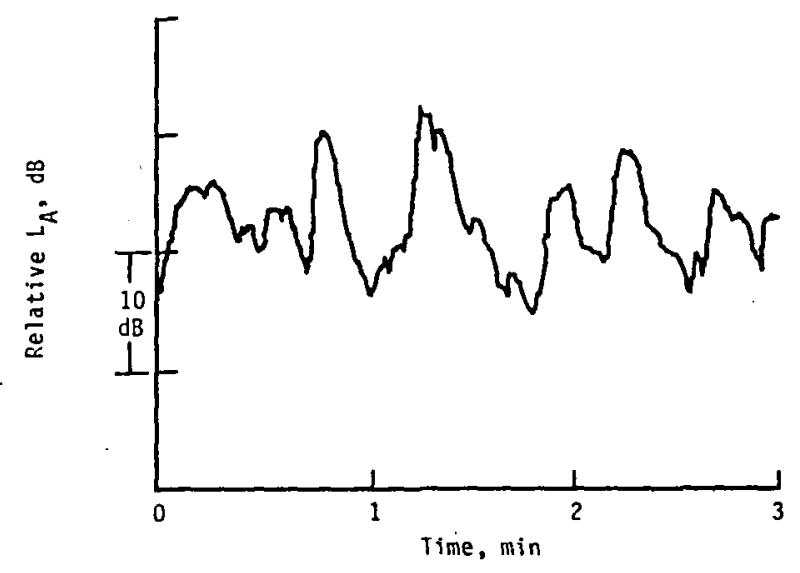

(b) Traffic.

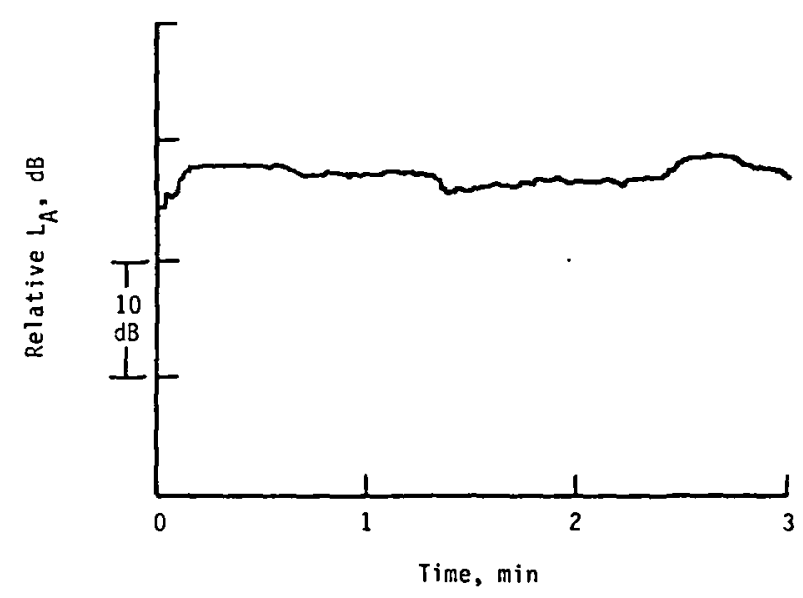

(c) Air conditioner.

Figure 3.- Time histories of stimuli. 


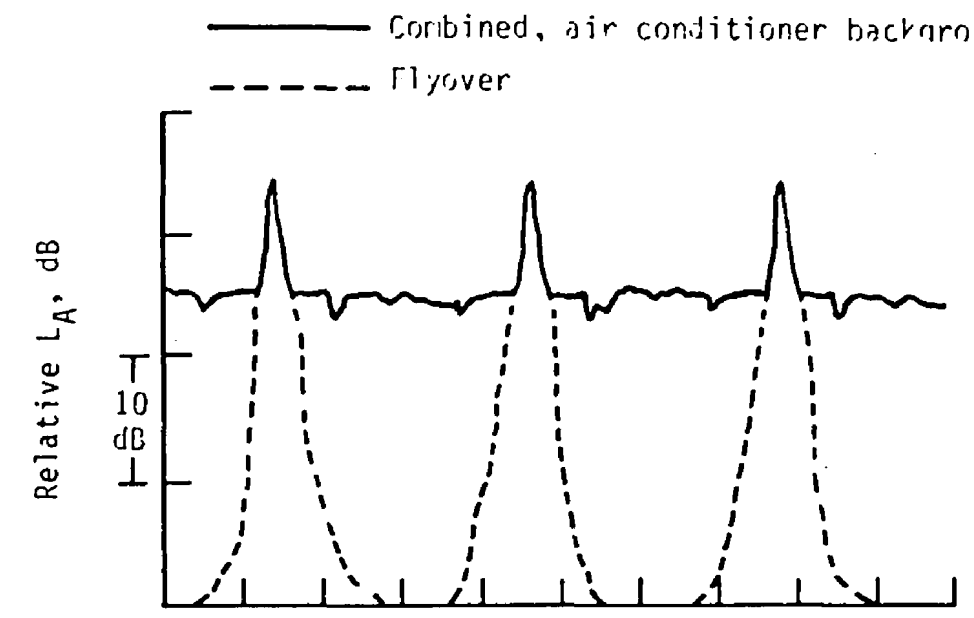

(a) $S / N=-3 d B$

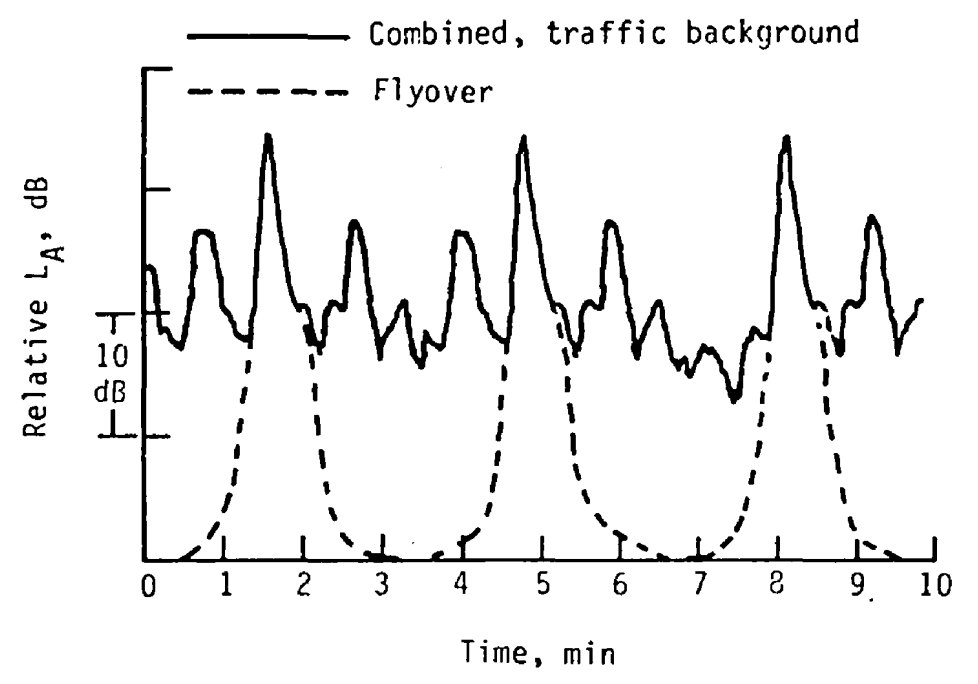

(c) $S / N=-3 d S$

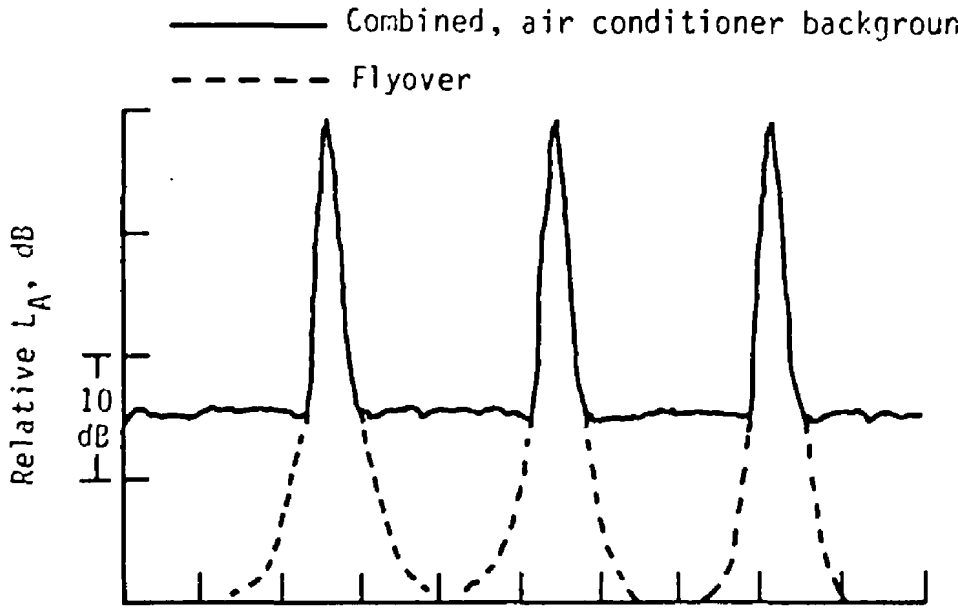

(b) $S / R=15 d e$

Combined, traffic background

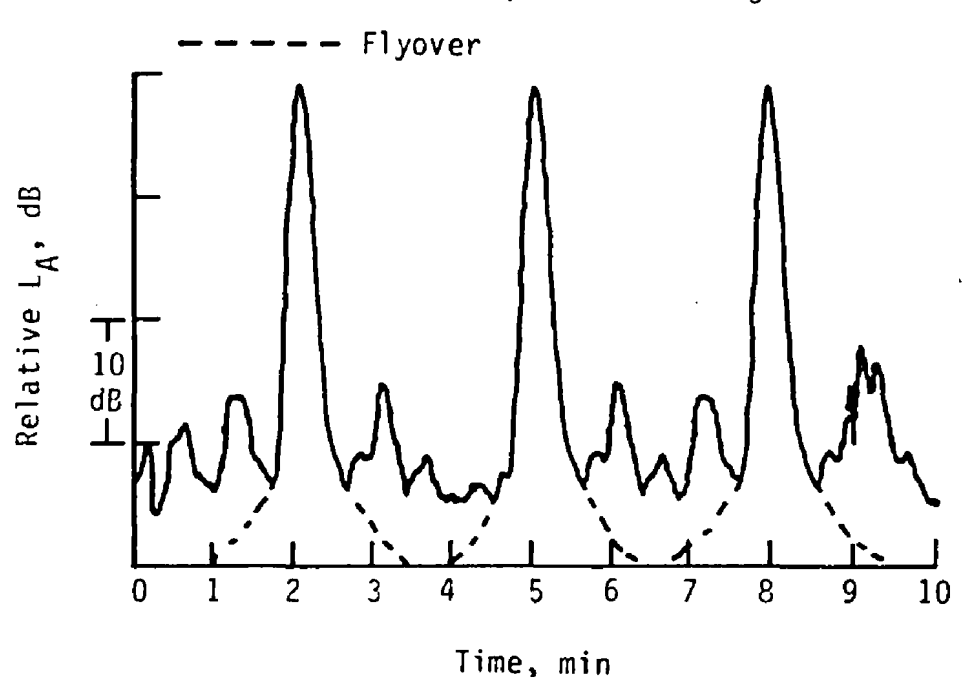

(d) $S / N=15 d B$ 


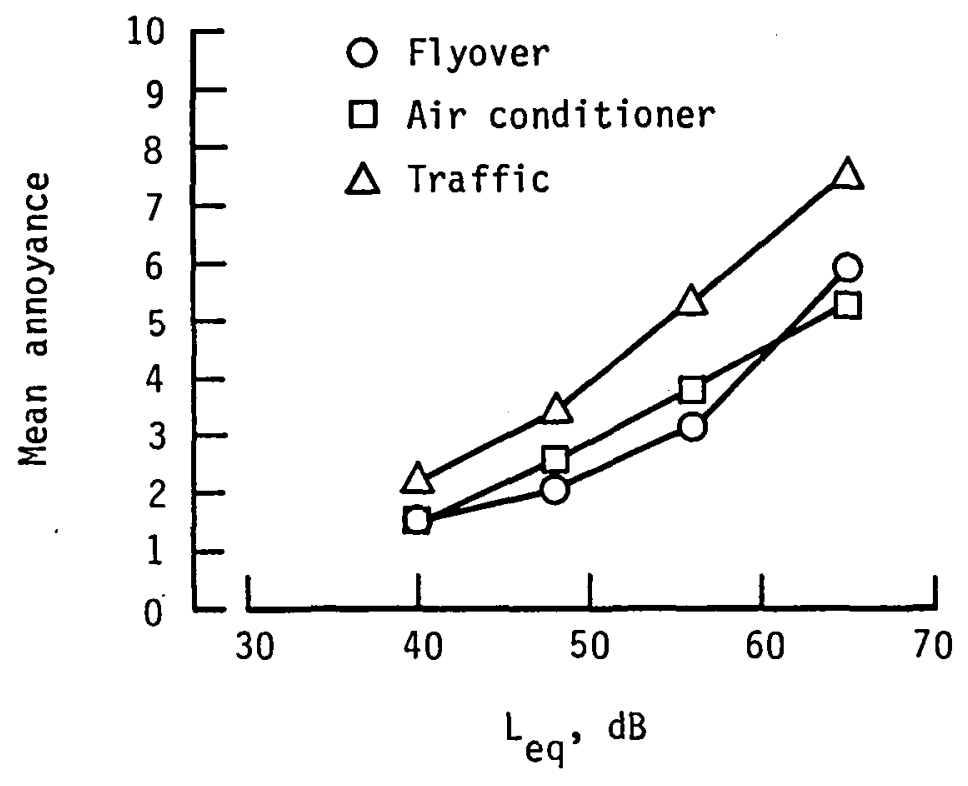

Figure 5.- Mean annoyance functions of individual sources. 


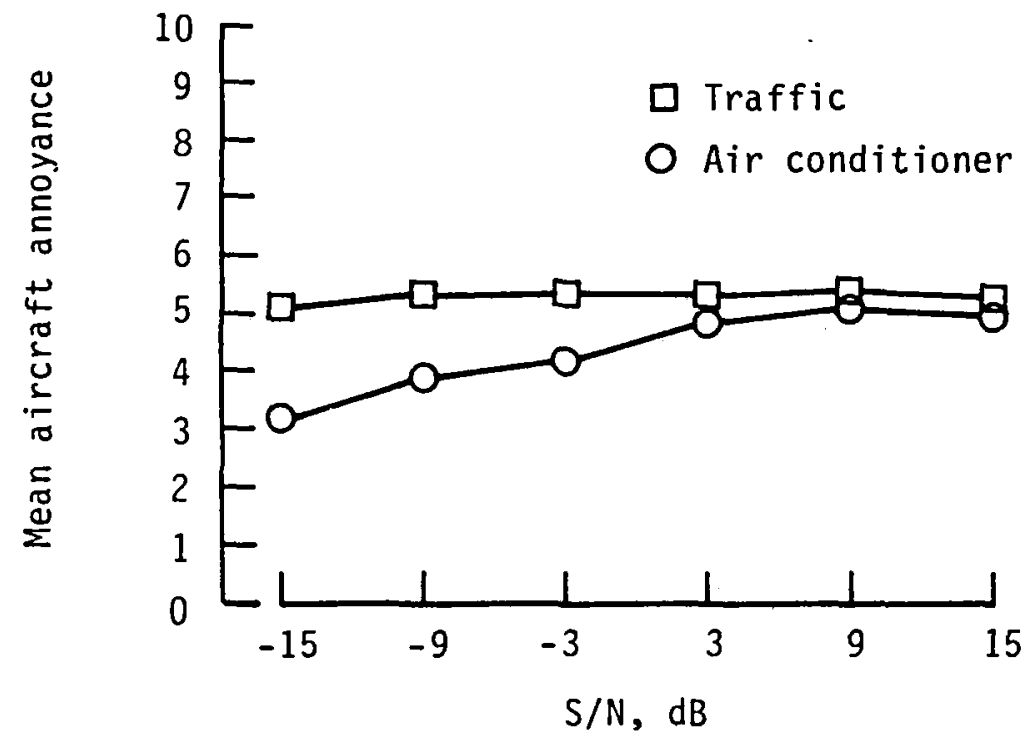

Figure 6.- Effect of background type on aircraft annoyance. 


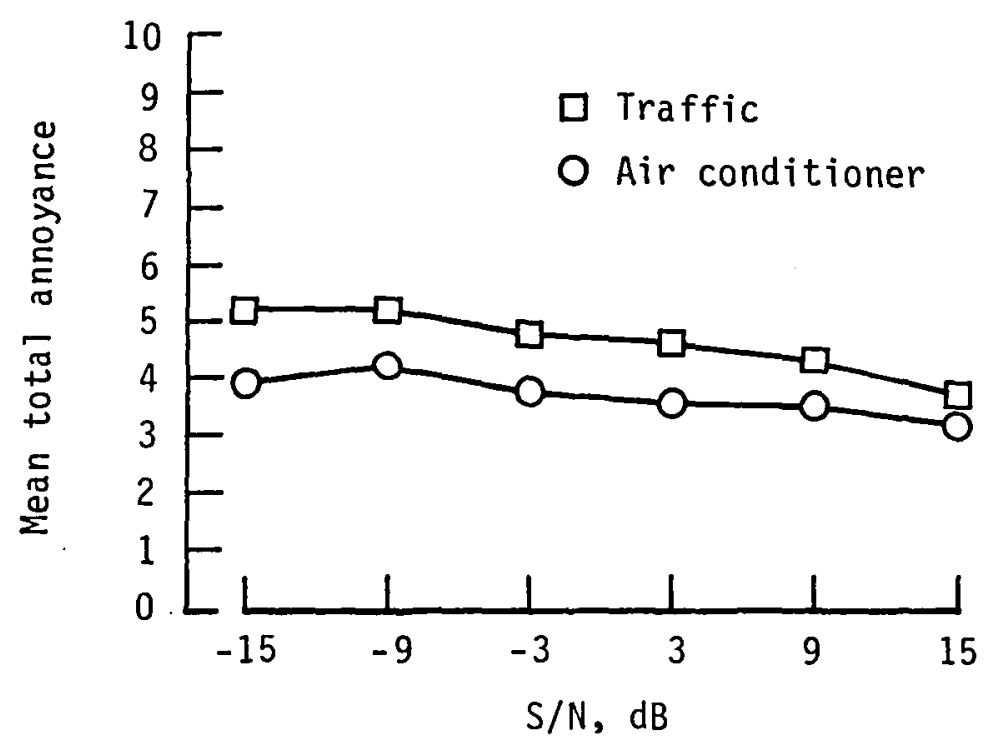

Figure 7.- Effect of background type on total annoyance. 


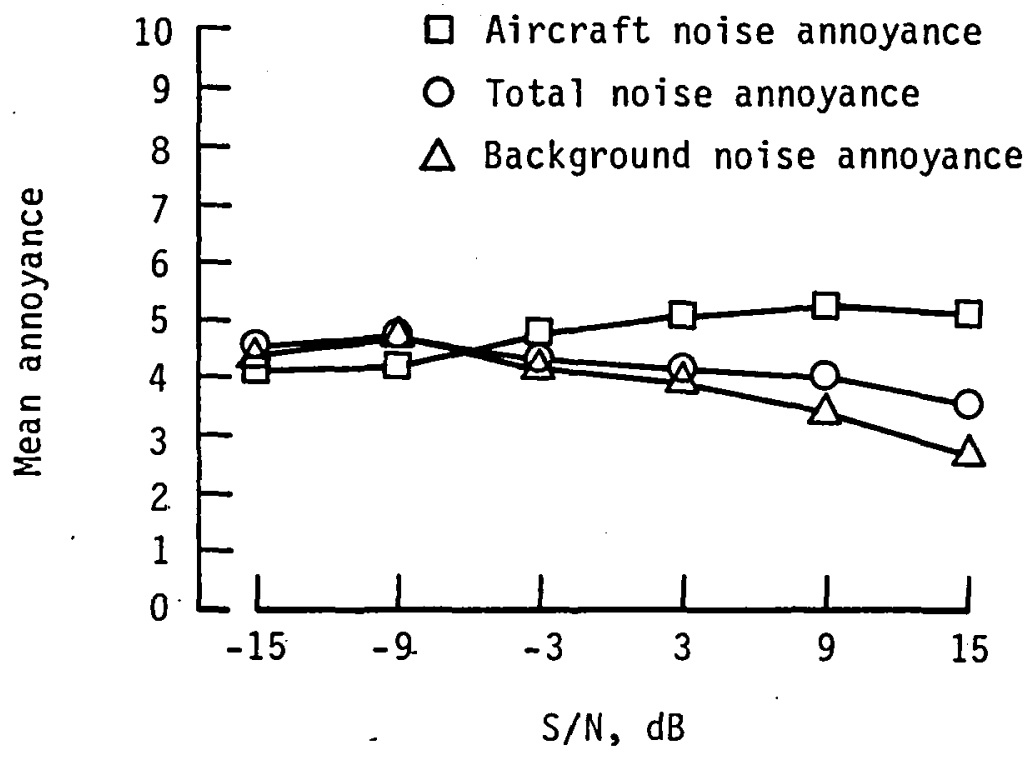

Figure 8.- Effect of $S / N$ on total and source specific annoyance, for constant Leq. 


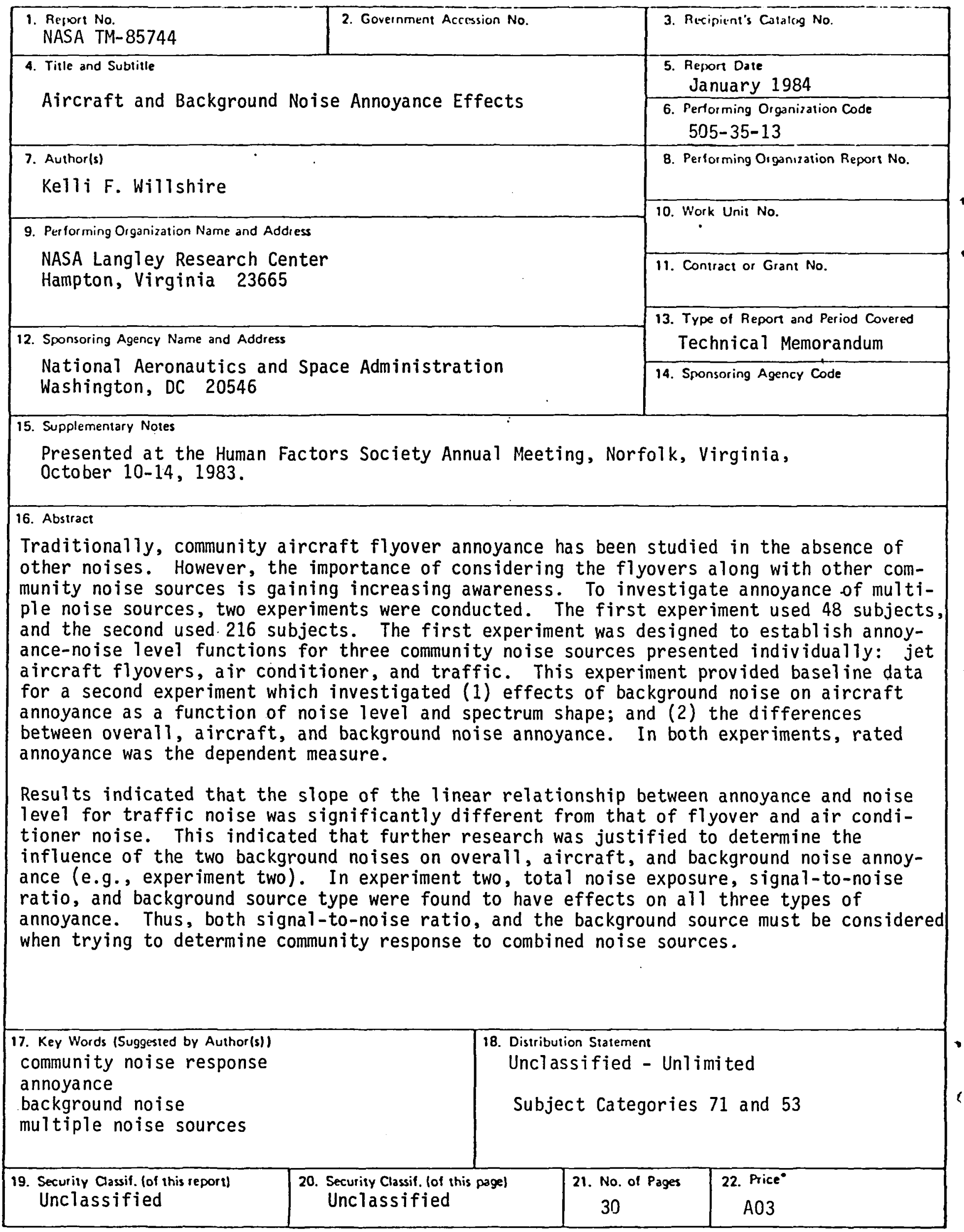

- For sale by the National Technical Information Service. Springfield. Virginia 22161 


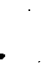

